\section{Medical interest of 3D reconstructed limb to build a customized multicomponent bandage for the treatment of a lower limb lymphedema with partially amputated calf: a case report}

\section{Frédéric Pastouret \\ Compression Therapy Research Unit,} Papignies, Belgium

\section{Introduction}

Multicomponent bandage (MCB) is an essential method in the treatment of lower leg lymphedemas. ${ }^{1,2}$ However, 2 layers bandages applying methods proposed by manufacturers do not result in selected pressures nor in a digressive pressure gradient and the proposed methods are not adapted for each type of case. For some particular lymphedema's patients, the therapist has to find a bandage applying method to obtain specific therapeutic criteria as the final stiffness of the assembled bandage, the expected pressure and a specific pressure gradient.

\section{Objective}

The aim of this study is to build a customized multicomponent bandage with selected pressures and a digressive pressure gradient for a patient with lymphedema and partially amputated calf (Figure 1). The patient underwent a lymphatic system infection of her right lower limb with partial inguinal node dissection, aggravated by a sepsis and a calf subcutaneous tissue infection. She cannot stand high-pressure levels on her limb, usually used during multicomponent bandage treatment for lymphoedema patient.

\section{Materials and Methods}

This experiment was conducted in 2 phases; first, on the $3 \mathrm{D}$ reconstructed lower limb and second on the patient herself.

- From the simulated limb, a very light foam prosthesis of the partial amputated right calf was customized in order to fill in the loss of the calf tissue under the future bandage. A $2 \mathrm{~mm}$ thickness custom silicone pad (medi ${ }^{\circledR}$ silicone for custom made liners, density A-5) was designed to be the protective skin interface layer of the prosthesis (Figure 2). . $^{3,4}$

Pressure sensors were applied at 10 dif- ferent selected points (Figure 2). Multicomponent bandage consists on a first layer of tubular cotton jersey put directly on the skin, a second single layer of Mobiderm ${ }^{\circledR}$ (minimal overlap, no tension) and a last single layer of Biplast ${ }^{\circledR}$. Biplast ${ }^{\circledR}$ overlap method was adapted with a constant band tension to obtain 20-25 $\mathrm{mmHg}$ at dorsal face of the foot (100\% of pressure) and a digressive pressure gradient on the rest of the limb (2/3 overlap at the foot, calf and knee distal part; $1 / 2$ overlap at the tight) (Figure 3). The foam prosthesis was placed on the silicone pad which was directly applied on the simulated limb under the multicomponent bandage.

- Bandage applying method was finally tested on the patient (Figure 3). Pressures were assessed in the same 10 locations on the patient's own right limb in standing position and during walking. Dynamic variation pressure indexes (DVPI) were calculated at each selected points (difference between maximal pressures and minimal pressures during walking), which represent the local massage effect or pump effect under bandage.

\section{Results}

On the $3 \mathrm{D}$ reconstructed member and on the patient, selected pressures at dorsal face of the foot was respectively $20 \mathrm{mmHg}$ and $23 \mathrm{mmHg}$. Global internal and external digressive pressure gradients (Int PG, Ext PG) were also obtained with the selected applying method (Figure 4).

On the patient, DVPI (mmHg) demonstrated high massage/pump effects at the dorsal foot face (16), above the malleoli (86 ) and under the prosthesis (16), due to the final resistance of the assembled bandage. The customized multicomponent bandage was well tolerated by the patient during experiment.
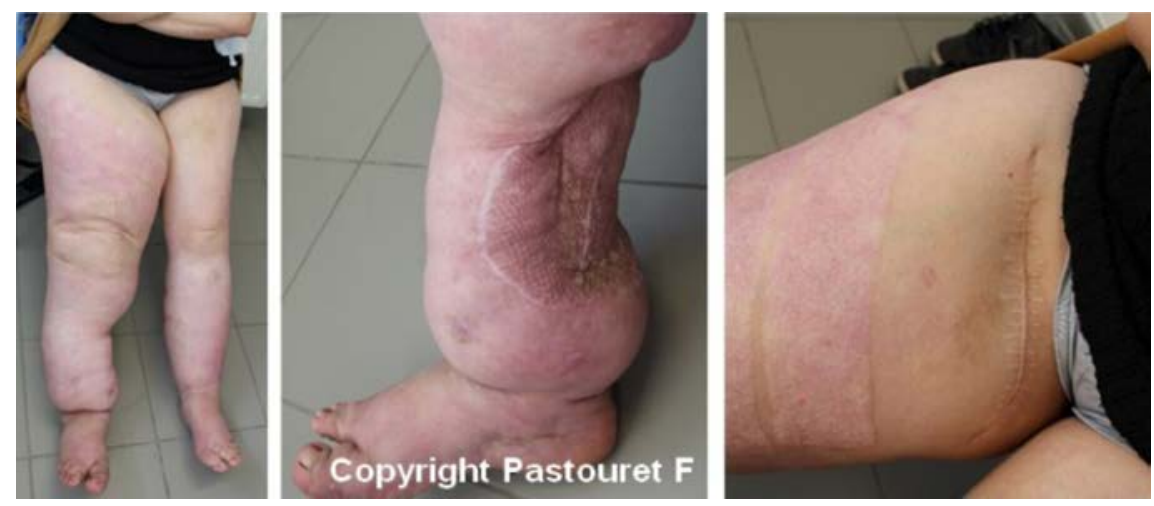

Figure 1. View of the patient lower limbs (left), her partially amputated calf and her thigh and her inguinal node dissection scar.
Correspondence: Frédéric Pastouret, Compression Therapy Research Unit, Papignies, Belgium.

E-mail: compressiontherapy.researchunit@outlook.com

This work is licensed under a Creative Commons Attribution 4.0 License (by-nc 4.0).

CCopyright F. Pastouret, 2017

Licensee PAGEPress, Italy

Veins and Lymphatics 2017; 6:6634

doi:10.4081/vl.2017.6634

\section{Discussion}

Patient was previously treated by another therapist with multicomponent bandage including high pressures. It was a failure because she did not support high pressures (or common pressures used for a lymphoedema patient) especially at the thigh level due to the skin graft. For this reason, the higher tolerated pressure was evaluated on her foot during the first appointment. This low pressure was selected as the pressure reference at the dorsal foot face for her customized multicomponent bandage. Having a previous satisfactory experience concerning multicomponent bandages applied with very low pressures and global digressive pressure gradient for lymphoedema patients (Leduc's method), those two pressure paramaters were the solution to build a tolerated bandage for the patient.

Those pressures were possible to obtain due to the selected applying method, the global conic shape and the circular section all along the limb.

In this case, recorded DVPI during walking were not only due to the final stiffness of the assembled bandage, but also to the limb volume change. The patient walking difficulties (inability to bend the knee) and the amputated calf explain the poor" 
DVPI at the tight level.

Silicone pad was selected as a safety protective interface between skin graft and the prosthesis to reduce local mechanical stress on the calf skin scars (medical propriety used during scar management) $)^{4}$ but also for two other technical reasons (washable and reusable).
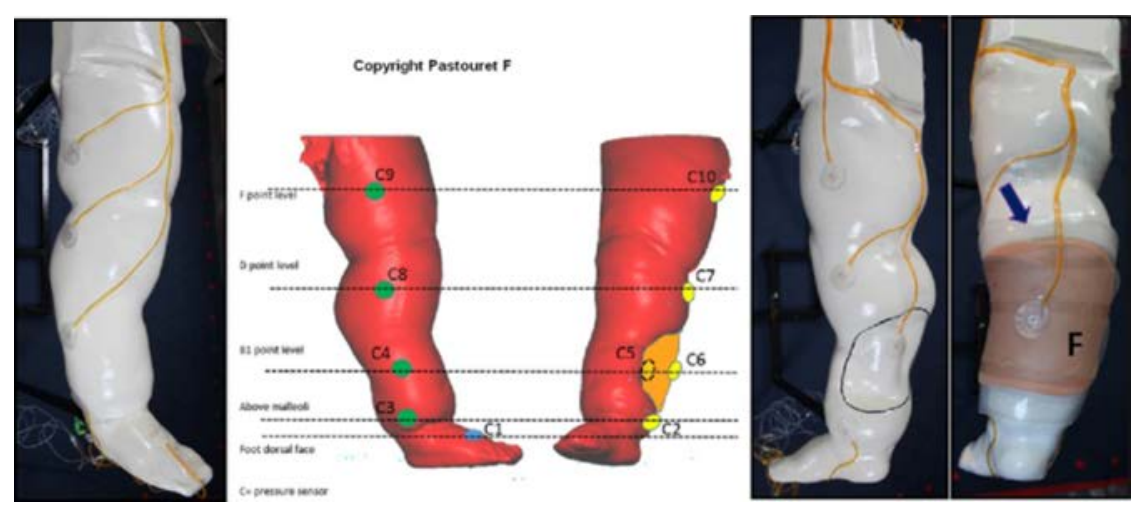

Figure 2. Pressure sensors locations on the $3 \mathrm{D}$ reconstructed limb. $\mathrm{C} 5$ is located under the silicone and the prosthesis. C6 on the prosthesis; Silicone pad: Medi® silicone for custom made liners, density A-5 (blue arrow); Light foam prosthesis of the partial amputated right calf $(\mathbf{F})$.
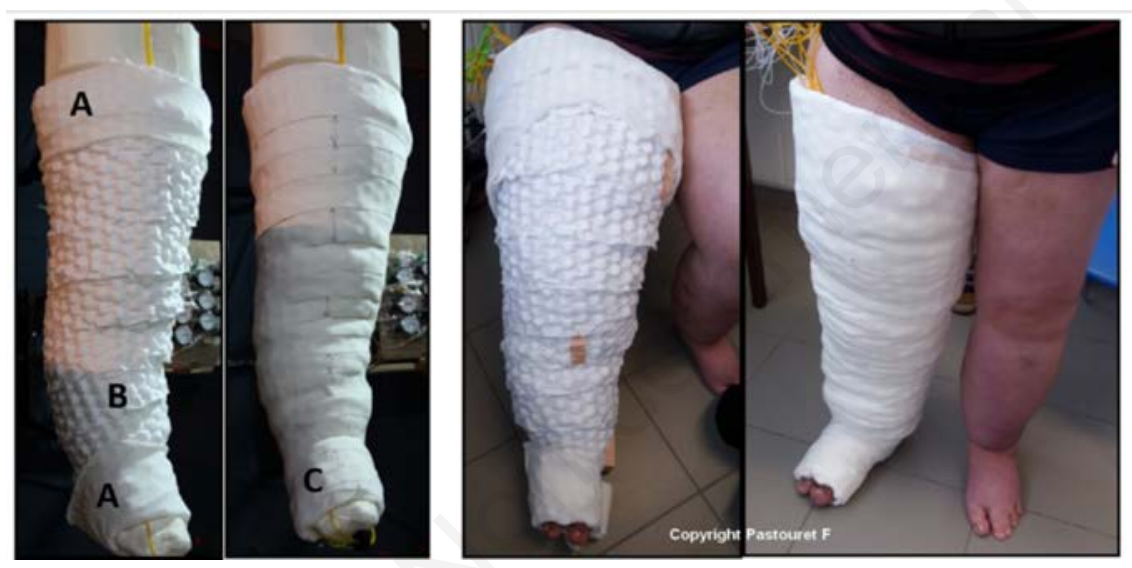

Figure 3. Multicomponent bandage applying method on the 3D reconstructed limb (left) and on the patient (right). First layer of tubular cotton jersey (A). Second single layer of Mobiderm ${ }^{\circledR}$, minimal overlap, no tension (B). last single layer of Biplast ${ }^{\circledR}$. Biplast ${ }^{\circledR}$, digressive overlap and constant band tension (C).

\begin{tabular}{|c|c|c|c|c|c|c|c|c|c|c|c|}
\hline \multirow[b]{3}{*}{ Sensors } & \multirow{2}{*}{\multicolumn{4}{|c|}{$\begin{array}{l}30 \text { reconstructed member } \\
3 \text { tries (mean and sd) }\end{array}$}} & \multicolumn{7}{|c|}{ Real member of the patient } \\
\hline & & & & & \multicolumn{4}{|c|}{ Rest } & \multicolumn{3}{|c|}{ DVPI mmHg (walking) } \\
\hline & Pressures & $\mathbf{x}$ & Int PG & Ext PG & Pressures $\mathrm{X}$ & & Int PG & Ext PG & Max P & $\operatorname{Min} \mathbf{P}$ & DVPI \\
\hline C1 foot & $20,3 \pm 1,5$ & $100 \%$ & $100 \%$ & $100 \%$ & 23 & $100 \%$ & $100 \%$ & $100 \%$ & 21 & 5 & 16 \\
\hline C2 Int Mall & $19 \pm 2$ & $95 \%$ & $95 \%$ & & 14 & $61 \%$ & $61 \%$ & & 15 & 7 & 8 \\
\hline C3 Ext Mall & $6 \pm 3,5$ & $30 \%$ & & $30 \pi$ & 10 & $43 \%$ & & 43\% & 13 & 7 & 6 \\
\hline C4 B1 ext & $8 \pm 1,7$ & $39 \%$ & & $39 \%$ & 13 & $56 \%$ & & $56 \%$ & 14 & 10 & 4 \\
\hline C5 B1 under prothesis & $1,3 \pm 1,1$ & $6 \%$ & & & 18 & $78 \%$ & & & 32 & 16 & 16 \\
\hline C6 B1 on prothesis & $8,7 \pm 1,1$ & $43 \%$ & & & 8 & $35 \%$ & & & 8 & 8 & 0 \\
\hline C7 D int & $10,7 \pm 0,6$ & $52 \%$ & $52 \%$ & & 10 & $43 \%$ & $43 \%$ & & 12 & 10 & 2 \\
\hline C8 D ext & $6 \pm 1$ & $30 \%$ & & $30 \%$ & 14 & $61 \%$ & & $56 \%$ & 12 & 12 & 0 \\
\hline C9 F ext & $5,7 \pm 1,1$ & $28 \%$ & & $28 \%$ & 8 & $35 \%$ & & $35 \%$ & 6 & 6 & 0 \\
\hline \multirow[t]{2}{*}{$\mathrm{C} 10 \mathrm{~F}$ int } & $7,6 \pm 0,6$ & $37 \%$ & $37 \%$ & & 10 & $43 \%$ & $43 \%$ & & 10 & 8 & 2 \\
\hline & $\mathrm{mmHg}$ & & & & $\mathrm{mmHg}$ & & & & $\mathrm{mmHg}$ & $\mathrm{mmHg}$ & $\mathrm{mmH}$ \\
\hline
\end{tabular}

Figure 4. Recorded pressures (mmHg or \%), internal and external pressure gradients (\%) and DVPI during walking, according the sensors location. (non-cohesive or cohesive MCB) at the disposal of the therapist.

For this patient, staying in the same standing position or walking during a long time was very difficult. Working on $3 \mathrm{~d}$ reconstructed limb was the solution to build a customized multicomponent bandage and offered the possibilities to practice multiple tests (products choice, best applying method). It was like having the patient in our lab.

\section{Conclusions}

The use of simulated limb in compression therapy in vitro experiment to assess related pressure parameters is common. ${ }^{6-9}$ Working on 3D reconstructed limb to prepare a customized multicomponent bandage for a specific patient is a new concept in compression therapy that allowed decreasing the patient time's investment.

Custom prosthesis with the silicone interface enabled to normalize the leg's shape, to protect the skin scars and to obtain a high massage/pump effect on the skin graft, which is a very important skin care benefit during the treatment. Final pressure, pressure gradients, DVPI and final resistance of assembled bandage are very satisfying and are leading to an optimal bandage tolerance by the patient.

\section{References}

1. International Society of Lymphology. The diagnosis and treatment of peripheral lymphedema: 2013 Consensus Document of the International Society of Lymphology. Lymphology 2013;46:1-11.

2. Partsch H, Flour M, Smith PC. Indications for compression therapy in venous and lymphatic disease consensus based on experimental data and scientific evidence. Under the auspices of the IUP. Int Angiol 2008;27:193-219.

3. Ehrler SC, Eveno D. Résultats d'une étude multicentrique française concernant la mise en place d'un manchon Post opératoire en silicone chez 211 patients amputés du membre inférieur. J Orthoped 2009;10:1432-4.

4. Monstrey S, Middelkoop E, Vranckx JJ, et al. Updated scar management practical guidelines: non-invasive and invasive measures. J Plastic Reconstr Aesth Surg 2014;67:1017-25.

5. Quere I, Presles E, Coupe M, et al. Prospective multicentre observational study of lymphedema therapy: POLIT 
study. J Malad Vasc 2014;39:256-63.

6. Stolk R, Wegen van der-Franken CP, Neumann HA. A method for measuring the dynamic behavior of medical compression hosiery during walking. Dermatol Surg 2004;30:729-36; discussion 36.

7. Partsch H, Partsch B, Braun W.
Interface pressure and stiffness of ready made compression stockings: comparison of in vivo and in vitro measurements. J Vasc Surg 2006;44:809-14.

8. Gaied I, Drapier S, Lun B. Experimental assessment and analytical 2D predictions of the stocking pressures induced on a model leg by Medical
Compressive Stockings. J Biomechan 2006;36:3017-25.

9. Pastouret F. Pressures exerted by circular or flat knitted arm sleeves during simulated muscular contractions. 42nd ESL Congress, Mulhouse, France; 2016. p 67. 